\title{
Genetic Divergence in Landraces of Bangladesh Rice (Oryza sativa L.)
}

\author{
S. M. Hosan ${ }^{1}$, Nasrin Sultana ${ }^{2 *}$, K. M. Iftekharuddaula ${ }^{3}$, Md. Nasar Uddin Ahmed ${ }^{2}$ and \\ Shamim $\mathrm{Mia}^{4}$ \\ ${ }^{1}$ Biotechnology Division and ${ }^{3}$ Plant Breeding Division, Bangladesh Rice Research Institute \\ Gazipur-1701, Bangladesh \\ ${ }^{2}$ Dept. of Genetics and Plant Breeding and ${ }^{4}$ Dept. of Agronomy, Patuakhali Science \\ and Technology University, Patuakhali, Bangladesh \\ *Corresponding author and Email: nsazad@yahoo.com
}

Received: 13 October 2010

Accepted: 17 March 2011

\begin{abstract}
Twenty rice landraces collected from different ecological regions of Bangladesh were studied to assess the nature and magnitude of genetic divergence among them. Based on twelve characters, the genotypes were grouped into five clusters. No parallel relationship between genetic and geographical divergence was observed. Inter-cluster distances were higher than the intra-cluster distances reflecting wider genetic diversity among the genotypes of different groups. The genotypes under cluster IV showed highest divergence among them as it exhibited highest intra-cluster distance. High level of inter-cluster distance was found between cluster II and V and between cluster I and III. Number of filled grains number /panicle, number of panicles/plant, biomass index and grain yield contributed considerably towards total divergence. Germplasm having these characters in the genetically distant cluster could, therefore, offer a significant scope for the development of high yielder through judicious selection.
\end{abstract}

Keywords: Genetic divergence, cluster, landrace, rice (Oryza sativa L.)

\section{Introduction}

Bangladesh is a good source of landraces of rice. Landraces comprise of the unique source for gene of high adaptability but are poor yielders. Therefore, it is an indispensable demand for varietal improvement in such situation. To formulate a sustainable breeding program precise knowledge about genetic divergence for yield components is a crucial one as varietal improvement depends mainly on the selection of parents with high genetic divergence in hybridization which is supposed to increase the chance of obtaining maximum heterosis and give broad spectrum of variability in segregating generations. But information on systematic research in this regard is very much limited or fragmentary. Therefore, the present investigation was undertaken to estimate the nature and magnitude of genetic divergence and the characters contributing to genetic diversity of some landraces of rice of Bangladesh.

\section{Materials and Methods}

Twenty landraces of rice were collected from different agro-ecological regions of Bangladesh (Table 1). The genotypes were grown at the experimental field of Patuakhali Science and Technology University during the T-aman season in 2009 using RCB design with three replications. Thirty five days old seedlings from each entry were planted in $4 \mathrm{~m} \times 2.5 \mathrm{~m}$ plot with $25 \mathrm{~cm} \times 15 \mathrm{~cm}$ spacing using single seedling per 
hill. All necessary cultural operations and management practices were employed as and when necessary. At maturity, $6 \mathrm{~m}^{2}$ area was harvested for estimating grain yield excluding border area and yield was adjusted at $14 \%$ moisture level. Observations were made from ten randomly selected plants and data were taken on seedling height at $25^{\text {th }}$ day ( $\left.\mathrm{SH}\right)$, days to maturity (DM), plant height (PH), number of panicles/plant (PN), ineffective tillers/plant (IET), panicle length in $\mathrm{cm}$ (PL), filled grain /panicle (FGN), spikelet sterility percentage (SS), thousand grain weight in gm (TGW), biomass index (BIO), flag leaf area (FLA) and grain yield in (GY). Mean data for each character were subjected to both univariate and multivariate analysis. For univariate analysis, analysis of variance was done individually by $\mathrm{F}$ test. Genetic diversity was worked out following principal component analysis ( Rao, 1964 ) and Mahalanobis' ( 1936 ) generalized distance ( $D^{2}$ ) analysis extended by Rao ( 1952 ). Clustering of genotypes was done according to Tochers method ( Rao, 1952 ). Multivariate analysis viz. principal component analysis, principal coordinate analysis, cluster analysis were performed using GENSTAT 5.13 program.

Table1. List of Genotypes with their place and date of collection

\begin{tabular}{|c|c|c|c|}
\hline Sl no. & Genotypes & Place of Collection & Date of collection \\
\hline 1 & Indrasail & Dhaka, Mymensingh, Faridpur, Jamalpur & April, 2009 \\
\hline 2 & Dadshar & Dhaka, Mymensingh, Natore, Rangpur & February, 2008 \\
\hline 3 & Latisail & Noakhali, Faridpur & September, 2007 \\
\hline 4 & Dhepa & Pabna, Sirajganj & May, 2007 \\
\hline 5 & Tilockachari & Chittagong, Dhaka & January, 2009 \\
\hline 6 & Nizersail & Dhaka, Faridpur, Pabna & March, 2007 \\
\hline 7 & Gobura & Jamalpur & May, 2008 \\
\hline 8 & Kartiksail & Manikganj, Dhaka, Comilla, Chittagong, Sylhet, Jessore & February, 2007 \\
\hline 9 & Jhingsail & Dhaka,Faridpur,Kushtia & April, 2009 \\
\hline 10 & Morichsail & Manikganj,Meherpur & August, 2008 \\
\hline 11 & Apchaya & Dhaka & September, 2008 \\
\hline 12 & Rajasail & Barisal, Comilla,Norail & December, 2007 \\
\hline 13 & Lalrodadhan & Dhaka & January, 2008 \\
\hline 14 & Hatisail & Dhaka,Satkhira & April, 2009 \\
\hline 15 & Jessorbalam & Jessore & February, 2008 \\
\hline 16 & Patnai & Barisal, Bakerganj & April, 2009 \\
\hline 17 & Lotha & Dhaka & September, 2007 \\
\hline 18 & Kamari & Khulna & May, 2008 \\
\hline 19 & Holdijharan & Dhaka & April, 2007 \\
\hline 20 & Maliabhangor & Dhaka & October, 2008 \\
\hline
\end{tabular}




\section{Results and Discussion}

The analysis of variance revealed that the genotypes differed significantly for all the characters studied indicating the presence of notable genetic variability among them. This implied that it would be judicious to classify the population on the basis of degree of divergence.

On the basis of degree of divergence, twenty genotypes were grouped into five clusters (Table 2). Distribution pattern indicated maximum number (6) of genotypes included in cluster II and the minimum (2) in cluster V. Cluster I, III and IV consisted of 5, 3 and 4 genotypes, respectively. The clustering pattern of the genotypes under this study didn't follow their geographical distributions. Genotypes within the same cluster were originated from different geographic regions. This indicates that although genetic diversity is generally associated with geographical diversity, the former is not necessarily directly related to geographic distribution rather they did not follow the same trend and factors other than geographical separation are also responsible for divergence which might be due to genetic drift, selection and continuous exchange of genetic materials among the countries of the world. Non corresponding genetic diversity and geographic distribution were also reported earlier by Mannan et al. (1993), Sinha et al. (1991), De et al. (1988), Choudhury et al. (1999), Masud et al. (2003) and Chandra et al (2007). Considering this, parents should be selected on the basis of genetic diversity rather than geographic diversity which are supported by Hasan et al. (2000).

Shanmugam and Rangasamy (1982) reported that grouping of materials of same origin into different clusters was an indication of broad genetic base of the genotypes belonging to that origin. Therefore, varieties originating from same place may have different genetic architecture or vice-versa. Statistical distances represent the index of genetic diversity among the clusters. The inter-cluster distances in all of the cases were higher than that of intracluster distances suggesting wider genetic diversity among the genotypes of different groups (Table 3 ).

Table 2. Distribution of 20 rice genotypes in different clusters

\begin{tabular}{|c|c|c|c|}
\hline $\begin{array}{l}\text { Cluster } \\
\text { no. }\end{array}$ & $\begin{array}{l}\text { Genotype serial } \\
\text { number }\end{array}$ & $\begin{array}{l}\text { Total number of } \\
\text { genotypes }\end{array}$ & Names of genotypes with place of collection \\
\hline I & $3,5,6,19,20$ & 5 & $\begin{array}{l}\text { Latisail (Noakhali, Faridpur), Tilockachari } \\
\text { (Chittagong, Dhaka), Nizersail (Dhaka, Faridpur, } \\
\text { Pabna), Holdijharan (Dhaka), } \\
\text { Maliabhangor (Dhaka) }\end{array}$ \\
\hline II & $1,2,4,11,15,16$ & 6 & $\begin{array}{l}\text { Indrasail (Dhaka, Mymensingh, Faridpur, Jamalpur), } \\
\text { Dadshar (Dhaka, Mymensingh, Natore, Rangpur), } \\
\text { Dhepa (Pabna, Sirajganj), Apchaya (Dhaka), } \\
\text { Jessorbalam(Jessore), Patnai (Barisal, Bakerganj) }\end{array}$ \\
\hline III & $9,10,13$ & 3 & $\begin{array}{l}\text { Jhingsail (Dhaka, Faridpur, Kushtia), Morichsail } \\
\text { (Manikganj, Meherpur), Lalrodadhan (Dhaka) }\end{array}$ \\
\hline IV & $7,12,14,18$ & 4 & $\begin{array}{l}\text { Gobura (Jamalpur), Rajasail (Barisal, Comilla, } \\
\text { Norail), Hatisail (Dhaka, Satkhira), Kamari } \\
\text { (Khulna) }\end{array}$ \\
\hline $\mathrm{V}$ & 8,17 & 2 & $\begin{array}{l}\text { Kartiksail (Manikganj, Dhaka, Comilla, } \\
\text { Chittagong, Sylhet, Jessore), Lotha (Dhaka) }\end{array}$ \\
\hline
\end{tabular}


Table 3. Average intra (bold) and inter-cluster distances $\left(D^{2}\right)$ for 20 rice genotypes

\begin{tabular}{lccccc}
\hline Clusters & I & II & III & IV & V \\
\hline I & $\mathbf{0 . 7 3 1}$ & 69.37 & 84.99 & 10.58 & 12.48 \\
II & & $\mathbf{0 . 5 9 1}$ & 68.92 & 55.43 & 96.76 \\
III & & $\mathbf{0 . 5 4 7}$ & 61.00 & 11.84 \\
IV & & & $\mathbf{0 . 7 6 7}$ & 11.37 \\
V & & & & $\mathbf{0 . 5 0 8}$ \\
\hline
\end{tabular}

Similar trend was found by Iftekharuddaula et al. (2002). The intra-cluster $\mathrm{D}^{2}$ values in all the five clusters were low indicating the genotypes within the same clusters were closely related. The intra-cluster distance was maximum in cluster IV and minimum in cluster V denoting the genotypes under cluster IV were most diversed and those of cluster $\mathrm{V}$ were comparatively similar.

The inter-cluster $\mathrm{D}^{2}$ values ranged from 10.58 to 96.76 which indicates implies wide range of diversity. Regarding the inter-cluster distance, maximum genetic distance was observed between cluster II and cluster V followed by that between I and III indicating that genotypes in II were far diversed from those of $\mathrm{V}$ and the genotypes of I from those of III. Choosing of genotypes belonging to distant clusters were expected to execute maximum heterosis in crossing and to be used in hybridization program for obtaining a wide spectrum of variation among the segregants. Similar conclusions were also reported by Hossain et al. (2003). Intermediate cluster distances were observed for cluster II with cluster I, III and IV. Cluster III was also in intermediate distance with cluster IV. It may be expected that crossing involving parents from the medium divergent clusters also exhibit significant heterotic segregants for yield and some of its components (Mian and Bhal, 1989). The minimum inter-cluster distance was observed between cluster I and IV followed by that between IV and $\mathrm{V}$ denoting that the genotypes of these cluster were somewhat close.
Cluster means for 12 characters and the relative contribution of different characters towards divergence are demonstrated in Table 4. Ineffective tillers/plant, number of panicles/plant, filled grains/panicle and biomass index were found to be potential contributors to genetic divergence in the genotypes. Similar trend was found by Selvakumar et al. (1989), Iftekharuddaula et al. (2002) and Sabesan et al. (2010) in rice.

The highest cluster mean was observed in cluster III for days to maturity, seedling height at $25^{\text {th }}$ day, plant height, panicle length, biomass index and flag leaf area; in cluster I for number of filled grain/panicle and grain yield; in cluster IV for number of panicles/plant and in cluster $\mathrm{V}$ for thousand grain weight. Mean performance of different clusters also revealed that for number of panicles/plant and panicle length, cluster III and cluster IV were the most diversed genotype groups. Again, cluster III and V were most diversed for days to maturity, cluster III and I for seedling height, cluster III and V for plant height, cluster I and IV for filled grain number/panicle, cluster II and V for thousand grain weight, cluster III and V for biomass index, cluster II and III for flag leaf area and cluster I and V for grain yield. Cluster II comprised of the genotypes with second highest number of panicles/plant, days to maturity, seedling height, number of filled grains/panicle and grain yield. Cluster I ranked second with the genotypes for plant height, panicle length, biomass index and flag leaf area. The lowest performed genotypes for more number of characters were included under cluster $\mathrm{V}$. 
Table 4. Cluster means with inter-cluster CV (\%) for 12 characters of 20 genotypes

\begin{tabular}{llccccc}
\hline \multirow{2}{*}{ Characters } & \multicolumn{7}{c}{ Clusters } & CV\% \\
\cline { 2 - 6 } & \multicolumn{1}{c}{ I } & II & III & IV & V \\
\hline Days to maturity & 137.00 & 140.00 & 140.33 & 134.50 & 111.50 & 0.37 \\
Seedling height at $25^{\text {th }}$ day in cm & 45.34 & 48.58 & 50.73 & 45.57 & 45.70 & 3.94 \\
Plant height in cm & 137.26 & 127.75 & 144.80 & 128.53 & 122.15 & 3.69 \\
Number of panicles/plant & 8.36 & 9.18 & 8.13 & 9.70 & 8.20 & 15.08 \\
Ineffective tiller number/plant & 1.90 & 2.12 & 2.10 & 2.25 & 1.80 & 28.69 \\
Panicle length in cm & 23.52 & 21.95 & 24.37 & 20.52 & 20.70 & 4.74 \\
Filled grain number /panicle & 82.68 & 63.25 & 59.10 & 46.05 & 48.75 & 20.53 \\
Spikelet sterility percentage & 22.80 & 29.85 & 46.23 & 36.53 & 25.65 & 29.39 \\
Thousand grain weight in gm & 25.18 & 23.53 & 25.32 & 26.80 & 27.92 & 1.82 \\
Biomass index & 41.02 & 39.78 & 45.28 & 34.09 & 32.49 & 15.87 \\
Flag leaf area in cm ${ }^{2}$ & 32.27 & 28.32 & 36.00 & 28.39 & 30.09 & 12.23 \\
Grain yield in t/ha & 2.01 & 1.83 & 1.64 & 1.63 & 1.41 & 15.41 \\
\hline
\end{tabular}

Table 5. Latent vectors for 12 characters of 20 rice genotypes

\begin{tabular}{lll}
\hline Characters & Vector I & Vector II \\
\hline Days to maturity & -0.0059 & 0.2249 \\
\hline Seedling height at $25^{\text {th }}$ day in cm & 0.0866 & -0.2707 \\
Plant height in cm & 0.0757 & 0.2561 \\
Number of panicles/plant & -0.4142 & 1.3505 \\
Ineffective tiller number/plant & -0.9047 & 0.0067 \\
Panicle length in cm & -0.4080 & -0.2563 \\
Filled grain number /panicle & -0.2961 & 0.0164 \\
Spikelet sterility percentage & 0.0030 & 0.1745 \\
Thousand grain weight in gm & -0.2513 & 0.3703 \\
Biomass index & 0.0486 & -0.0229 \\
Flag leaf area in cm & -0.1673 & -0.2318 \\
Grain yield in t/ha & 0.8922 & 1.3587 \\
\hline
\end{tabular}


The canonical variate analysis represents that in vector I, the important characters responsible for genetic divergence in the major axes of differentiation were seedling height, plant height, biomass index and grain yield (Table 5). In vector II days to maturity, plant height, number of panicles/plant, filled grain number/panicle, thousand grain weight played a major role. The more prominent role towards genetic divergence in both the vectors were found for plant height and grain yield. Besides, number of panicles/plant and thousand grain weight also contributed considerably towards genetic divergence. Hence, the aforementioned characters could offer a good scope of genetic improvement in rice. For yield improvement, these morphological and physiological parameters might be included as selection criteria.

The principal component analysis (PCA) showed that the first two components accounted for $71.06 \%$ of the total variation and a two dimensional scatter diagram was constructed using component 1 as $\mathrm{X}$-axis and component 2 as $\mathrm{Y}$-axis, reflecting the relative position of the genotypes (Fig. 1).

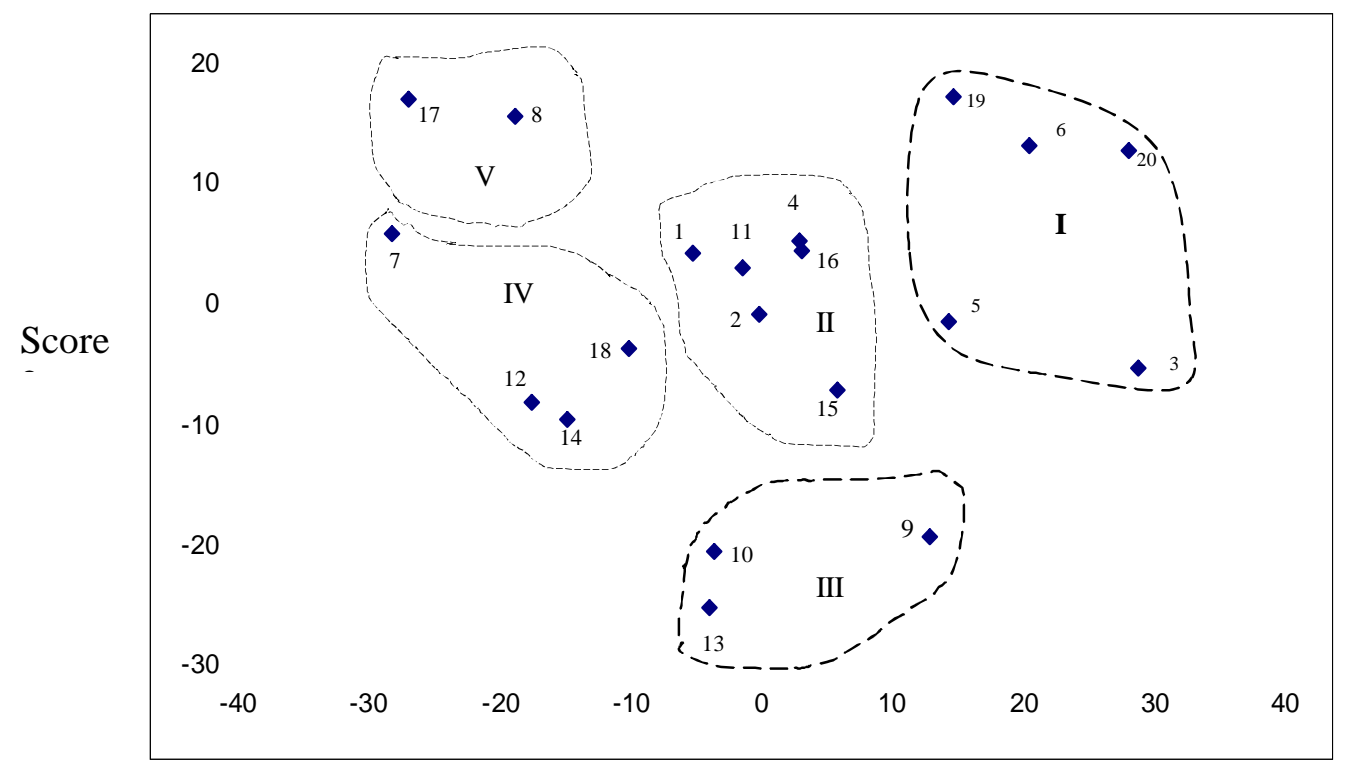

Score1

Fig. 1. Two dimensional scatter diagram representing distribution of 20 rice genotypes based on PCA scores superimposed with clustering from $\mathrm{D}^{2}$ analysis. 
The clustering pattern observed from $\mathrm{D}^{2}$ analysis were also reflected by this diagram. All the genotypes were grouped into 5 distinct cluster. The distribution pattern indicated that maximum number of genotypes were included in cluster II, while cluster $\mathrm{V}$ consisted of minimum. Analyzing all the results stated it was found that, genotypes in cluster III were important for panicle length, biomass index and flag leaf area while the genotypes of cluster IV were for number of panicles/plant and those in cluster I for number of filled grains/panicle.

\section{Conclusions}

It may be concluded that the greater genetic distance among the genotypes Gobura, Rajasail, Hatisail, Kamari, Jhingsail, Morichsail and Lalrodadhan in clusters should be prioritized for the development of high yielding rice varieties by exploitation of landraces.

\section{References}

Chandra, R., Pradhan, S. K., Singh, S., Bose, L. K. and Singh, O.N. 2007. Maltivariate analysis in upland rice genotypes. World Journal of Agricultural Sciences. 3(3):295-300.

Choudhury, D. A., Hamid, A., Bhowmik, A., Mian, G. U., and Islam, M. S. 1999. Genetic divergence in indigenous rice (Oryza sativa L.) varieties of Bangladesh. Bangladesh Journal of Plant Breeding and Genetics, 12(1\&2):33-36.

De, R. N., Setharam, R., Sinha, M. K. and Banarjee, S. P. 1988. Genetic divergence in rice. Indian Journal of Genetics, 48:189-194.

Hasan, M. J., Rasul, M. G., Mian, M. A. K., Hasanuzzaman, M. and Chowdhury, M. M. H. 2000. Genetic divergence of yam. Bangladesh Journal of Plant Breeding and Genetics. 13(1):07-11.

Hossain, M.A., Hamid, A., Hossain, S. M. A. and Bhuiyan, N. I. 2003. Genetic divergence and path analysis in groundnut. Bangladesh Journal of Plant Breeding and Genetics, 16(1):09-15.

Ifterkharuddaula, K. M., Akter, K., Bashar, M. K. and Islam, M. R. 2002. Genetic parameters and cluster analysis of panicle traits in
Hosan et al./The Agriculturists 8(2): 28-34 (2010) irrigated rice. Bangladesh Journal of Plant Breeding and Genetics. 15(1):49-55.

Mahalanobis, P. C.1936. On the generalized distance in statistics. Proceedings of the National Academy of Sciences of India, 2:49-55.

Mannan, M. A., Ahmed, M. S., Rashid, M. M., Bhuiyan, M. K. R. and Gomes, R. 1993. Genetic diversity of Colocasia esculenta L. Indian Journal of Root Crops, 19(2):95-99

Masud, M. A. T., Hossain, M. A., Saha, S. R., Muhammad, A. and Hossain, S. M. M. 2003. Genetic divergence in ridge gourd (Luffa acutangula L.) Bangladesh Journal of Plant Breeding and Genetics, 16(2):17-22.

Mian, M. A. K. and Bhal, P. N. 1989. Genetic divergence and hybrid performance in chickpea. Indian Journal of Genetics, 49(1)119-129.

Rao, C. R. 1964. The use and interception of principal component analysis in applied research. Sankhya. Ser. A 22:317-318.

Rao, C. R. 1952. Advanced statistical methods in biometrical research. John Willey and Sons, Inc., New York

Sabesan, T., Saravanan, K. and Anandan, A. 2010. Genetic divergence analysis for certain yield and quality traits in rice (Oryza sativa L.) Grown in irrigated saline low land of annamalainagar, south india. Journal of Central European Agriculture, 10(4):405-410

Selvakumar,K. S., Soundrapandian, G. and Amirthadevarathinam, A. 1989. Genetic divergence for yield and yield componenets in cold tolerant rice. The Madras Agricultural Journal, 76(12):688-694

Shanmugam, A. S. and Rangasamy, S. R. S. 1982. Genetic diversity for quantitative characters in greengram (Vigna radiata L.) The Madras Agricultural Journal, 69(10):631-636.

Sinha, P. K., Chauhan,V. S., Prasad, K. and Chauhan, J. S. 1991. Genetic divergence in indigenous upland rice varieties. Indian Journal of Genetics, 51(1):47-5 
